\title{
Revista do

\section{A DEFENSORIA PÚBLICA NA GARANTIA DO ACESSO À JUSTIÇA}

\section{Rafael Nunes Pires Rudolfo ${ }^{1}$}

\section{RESUMO}

Este artigo busca analisar o direito fundamental de acesso à justiça, principalmente aos indivíduos hipossuficientes, bem como o papel da Defensoria Pública como facilitadora desse acesso. Para tanto, serão analisadas as questões do acesso à justiça e como a Defensoria Pública pode atuar para garantir tal direito. Foi utilizado o método indutivo, com as técnicas do referente e da pesquisa bibliográfica.

Palavras-chave: Acesso à justiça. Direitos fundamentais. Defensoria pública.

\section{THE PUBLIC DEFENDER IN THE ASSURANCE OF THE ACCESS TO JUSTICE}

\begin{abstract}
This article aims to analyze the fundamental right of access to justice, meanly for poor citizens; and the role of the Public Defender as a facilitator of this access. Will be analyzed the issues about the access to justice and how Public Defender can act to ensure this right. It was used the inductive method, with the techniques of the reference and the bibliographic review.
\end{abstract}

Keywords: Access to justice. Fundamental rights. Public defender.

\footnotetext{
1 Mestre em Ciência Jurídica pela Universidade do Vale do Itajaí (UNIVALI). Especialista em Direito Processual Civil. Especialista em Direito Penal e Processual Penal. Especialista em Gestão de Negócios Financeiros (MBA). Graduado em Direito. Graduado em Sistemas de Informação. E-mail: Rafaelnpr@tjsc.jus.br.
} 


\section{INTRODUÇÃO}

Com o advento do pós-positivismo, os direitos fundamentais ganharam relevância e protagonismo, de modo que já se encontram elencados no texto constitucional, nos moldes neoconstitucionalistas.

No atual cenário jurídico brasileiro, busca-se a garantia e a efetivação dos direitos fundamentais, no intuito de instaurar plenamente o Estado Democrático de Direito. Ocorre que de nada adianta a Constituição Federal elencar essa gama de direitos, se os cidadãos não tiverem acesso à justiça, ou mesmo, desconhecerem o fato de terem acesso à justiça. Se o problema não é a declaração de direitos, mas sim torná-los realidade, nada mais justo que uma defensoria pública atuante para tal.

Este artigo tem como objetivo analisar as principais questões referentes ao acesso à justiça, bem como a atuação da defensoria pública para garantir esse acesso.

A metodologia utilizada foi o método indutivo, com as técnicas do referente, da pesquisa bibliográfica e do fichamento.

\section{ACESSO À JUSTIÇA}

Quando se trata do "Acesso à Justiça", a primeira referência que vem à mente é a obra de mesmo nome, concebida por Mauro Cappelletti e Bryant Garth, fruto do não menos famoso Projeto de Florença. Afinal, foi justamente nessa obra que o tema em testilha, pela primeira vez, ficou em evidência no âmbito jurídico mundial. A partir dessa obra, o "acesso à justiça" não somente ganhou relevância, mas também embasamento para que fosse reconhecido como direito fundamental nos mais diversos arcabouços jurídicos, inclusive no brasileiro.

É imperioso salientar, destarte, a definição da expressão "acesso à justiça", extraída de sua obra inaugural:

A expressão "acesso à Justiça" é reconhecidamente de difícil definição, mas serve para determinar duas finalidades básicas do sistema jurídico - o sistema pelo qual as pessoas podem reivindicar seus direitos e/ou resolver seus litígios sob os auspícios do Estado que, primeiro, deve ser realmente acessível a todos; segundo, ele deve produzir resultados que sejam individual e socialmente justos. [...] $\mathrm{O}$ "acesso" não é apenas um direito social 
fundamental, crescentemente reconhecido; ele é, também, necessariamente, o ponto central da moderna processualística. Seu estado pressupõe um alargamento e aprofundamento dos objetivos e métodos da moderna ciência jurídica. (CAPPELLETTI; GARTH, 1988, p. 3-5).

No escólio do Ministro do STF Luis Roberto Barroso, o acesso à justiça consiste na possibilidade de as pessoas mais pobres levarem sua demanda a um tribunal, mesmo que elas não sejam expressivas economicamente e necessitem isenção de custos e assistência judiciária para a contratação de um advogado (BARROSO, 2014).

Na lição de Gomes Canotilho, "os direitos e interesses do particular determinam o próprio fim do direito de acesso aos tribunais, mas este, por sua vez, garante a realização daqueles direitos e interesses" (CANOTILHO, 2003, p. 497).

Ainda no intuito de conceituar a expressão, é mister salientar a lição magistral do Professor Boaventura de Sousa Santos:

O tema do acesso à justiça é aquele que mais directamente equaciona as relações entre o processo civil e a justiça social, entre igualdade jurídicoformal e desigualdade socio-econômica. No âmbito da justiça civil, muito mais propriamente do que no da justiça penal, pode falar-se de procura, real ou potencial, da justiça. Uma vez definidas as suas características internas e medido o seu âmbito em termos quantitativos, é possível compará-la com a oferta da justiça produzida pelo Estado. Não se trata de um problema novo. No princípio do século, tanto na Áustria como na Alemanha, foram frequentes denúncias da discrepância entre a procura e a oferta da justiça e foram várias as tentativas para a minimizar, quer por parte do Estado [...], quer por parte dos interesses organizados das classes sociais mais débeis [...]. Foi, no entanto, no pós-guerra que esta questão explodiu. Por um lado, a consagração constitucional dos novos direitos econômicos e sociais e a sua expansão paralela à do Estado de bem estar transformou o direito ao acesso efectivo à justiça num direito charneira, um direito cuja denegação acarretaria a de todos os demais. Uma vez destituídos de mecanismos que fizessem impor o seu respeito, os novos direitos sociais e econômicos passariam a meras declarações políticas, de conteúdo e função mistificadores. (SANTOS, 1986, p. 18).

Vale ressaltar que, no cenário jurídico brasileiro, o termo "acesso à justiça" algumas vezes é utilizado de forma equivocada. Não se pode olvidar que a aludida expressão não se confunde com "assistência jurídica" nem com "gratuidade de justiça". Trata-se de ideia bem mais ampla:

A expressão "acesso à justiça" não possui um significado unívoco na doutrina. Quando utilizada, ora se apresenta significando algo como a 
duração razoável do processo, ora como devido processo. Outro significado corriqueiramente atribuído diz com a assistência jurídica. Na verdade, a expressão "acesso à justiça" corresponde a todas aquelas noções, podendo-se afirmar com segurança que seu melhor conceito é aquele que não o confunde com o acesso ao Judiciário [...] É fora de dúvida que o tema da assistência jurídica figura como um dos mais importantes para o estudo do acesso à justiça. Mas não se trata de expressões sinônimas. A ideia de acesso à justiça é mais abrangente do que a de assistência jurídica. Esta se insere naquela. [...] o acesso à justiça pressupõe - mas não se confunde com - a cláusula da inafastabilidade da jurisdição. (REIS; ZVEIBIL; JUNQUEIRA, 2013, p. 17).

Nessa esteira é a concepção de Tarcijany Machado, segundo a qual a ideia do acesso à justiça não pode ficar limitada à "acessibilidade de órgãos judiciários, mas abrange todos os meios estatais e não estatais, judiciais e não judiciais, pelos quais os cidadãos efetivam seus direitos, solucionam seus litígios, obtêm reparação de ofensas e lesões [...]" (MACHADO, 2017, p. 8).

A abertura do Judiciário aos indivíduos hipossuficientes, que "antes não ingressavam nas nossas Cortes de Justiça por impossibilidade econômica e técnica, está diretamente relacionada à legitimidade para a propositura de ações judiciais, além, é claro, de outras questões estruturais e organizacionais do Sistema de Justiça" (FENSTERSEIFER, 2017, p. 111-112).

Atualmente o "acesso à justiça" no Brasil ocorre de forma mais ampla. Isso porque não se pode olvidar que o princípio da inafastabilidade da jurisdição, depreendido do inciso XXXV do Artigo $5^{\circ}$ da Constituição Federal de 1988, foi concebido como uma resposta ao regime militar, período no qual os atos do Poder Público não necessariamente eram apreciados pelo Poder Judiciário. Ou seja, na época em que foi forjado o aludido dispositivo, havia a preocupação de que os atos efetivamente passassem pelo crivo do Judiciário, ao passo que atualmente, ainda que de forma subjacente, acrescenta-se a ideia de se entregar uma tutela satisfatória ao cidadão. Aliás, a mesma ideia é reforçada no Código de Processo Civil, uma vez que o Artigo $3^{\circ}$ desse diploma legal possui redação similar ao do dispositivo constitucional em apreço.

No mesmo sentido é o pensamento de Maria Tereza Aina Sadek:

Saliente-se, uma vez mais, que acesso à justiça e sua democratização não significam apenas o alargamento, os caminhos e a saída pelas portas do Poder Judiciário. A inclusão de parcelas da população até então excluídas 
representa, principalmente, propiciar condições para o conhecimento e a apropriação de direitos. Nesse sentido, acesso à justiça equivale a inserção, a participação, a trilhar um caminho para a redução das desigualdades econômica, social e cultural. O Poder Judiciário não possui o monopólio da efetivação dos direitos e da resolução de conflitos. Não é a única porta de acesso à justiça. Outros espaços têm se constituído para a garantia de direitos e para a solução de controvérsias. Dentre essas instituições, deve-se citar o Ministério Público, a Defensoria Pública, além das organizações erigidas a partir de princípios orientados pela pacificação, como a conciliação, a mediação e a arbitragem (SADEK, 2014, p. 65).

Dito de outra forma, o acesso à justiça poderia ser definido como uma releitura do princípio do devido processo legal, já que viabiliza a plenitude de exercício de outros direitos.

O relatório produzido por Mauro Cappelletti e Brian Garth explora três "ondas" para o acesso à justiça, bem como seus respectivos obstáculos, os quais serão analisados a seguir.

\subsection{Ondas e Obstáculos}

Cappelletti e Garth (1988) elencam três barreiras ao acesso à justiça: obstáculo econômico (que se refere à incapacidade financeira); obstáculo organizacional (dificuldade da tutela coletiva de direitos); e obstáculo cultural (desconhecimento dos direitos). Diante dessas três barreiras, busca-se respectivamente: garantir que os pobres tenham acesso ao Judiciário; estabelecer a coletivização das demandas judiciárias; e defender a simplificação procedimental e a criação de meios alternativos de justiça.

É mister ressaltar que o obstáculo econômico se consubstancia na própria "essência da destinação constitucional da Defensoria Pública" (REIS; ZVEIBIL; JUNQUEIRA, 2013, p. 18). Acerca dos obstáculos econômicos, Boaventura de Sousa Santos preleciona que, embora seja cara para os cidadãos em geral, "a justiça civil é proporcionalmente mais cara para os cidadãos economicamente mais débeis" (SANTOS, 1986, p. 19). Ainda sobre os obstáculos econômicos, Cleber Francisco Alves assim aduz:

A finalidade primordial do instituto da Assistência Jurisdicional é [...] a de assegurar efetivo acesso à Justiça em favor daqueles que, de outro modo, ficariam privados do exercício desse direito. Com efeito, uma das principais barreiras que impedem o acesso aos serviços judiciais é a insuficiência de recursos financeiros necessários para custear as despesas respectivas, que 
abrangem normalmente as custas do processo e as despesas com advogados e outros profissionais jurídicos (ALVES, 2005, p. 209-210).

O obstáculo organizacional traduz-se na ideia de que a "sociedade brasileira, em razão de sua formação histórica, teria dificuldades de várias ordens para se organizar e, com isso, defender seus direitos de maneira coletiva”. O obstáculo cultural, por sua vez, se caracteriza pelo desconhecimento dos direitos. "A pessoa que desconhece seus direitos possui menos chances de fazê-los valer, afinal, ela sequer sabe que os possui” (REIS; ZVEIBIL; JUNQUEIRA, 2013, p. 18).

Neste diapasão, a distância dos cidadãos em relação ao acesso à justiça "é tanto maior quanto mais baixo é o estrato social a que pertencem e [...] tem como causas próximas não apenas factores econômicos, mas também factores sociais e culturais", ainda que "relacionados com as desigualdades econômicas". Para o autor, "quanto mais baixo é o estrato sócio-econômico do cidadão menos provável é que conheça advogado ou que tenha amigos que conheçam advogados". Santos aponta, além disso, a distância geográfica entre o lugar onde o cidadão pobre vive e a região onde predominantemente se concentram os tribunais e escritórios de advocacia das cidades (SANTOS, 1986, p. 20-21).

Analisadas as barreiras, vale ressaltar que há três “ondas renovatórias" do acesso à justiça, que surgem em contraponto aos seus respectivos obstáculos: acesso à justiça aos pobres; tutela coletiva; e enfoque do acesso à justiça.

Nesta senda, é válido destacar o pensamento de Vitovsky, que, aliás, aponta a existência de quatro ondas do acesso à justiça:

As "quatro ondas" do acesso à Justiça podem ser facilmente identificadas no novo Código. O auxílio aos pobres encontra-se nos artigos que tratam da gratuidade de justiça. As ações coletivas, a rigor, não são especificamente tratadas. Contudo, verifica-se o tratamento coletivo de direitos individuais com a busca de uniformização, de celeridade, de segurança, com a uniformização e estabilidade da jurisprudência, com os incidentes de demandas repetitivas. Isto é, o tratamento coletivo de tais ações refere-se à tentativa de uniformização de decisões reduzindo seu potencial de gerar multiplicação de processos fundados em idêntica questão de direito, causando grave insegurança jurídica e risco de existência de decisões conflitantes. Como define a Exposição de Motivos, o tratamento coletivo de tais ações encontra-se na busca da decisão paradigmática. Por sua vez, a "terceira onda", das soluções alternativas, está presente na previsão das audiências de conciliação e mediação, realizadas por conciliadores ou mediadores. A propósito, a "quarta onda" refere-se à previsão de tais profissões jurídicas, de conciliadores e mediadores judiciais. No tocante ao 
papel do juiz, o Código destaca seus deveres: celeridade, repressão ao ato atentatório, busca de conciliação, efetividade e dever de aplicação dos princípios constitucionais. A equidade permanece como somente aplicável quando prevista em lei. Além disso, reforça-se o dever de transparência do julgamento, na forma do art. 10. (VITOVSKY, 2015, p. 15-16).

É cediço que a mitigação dos obstáculos ao acesso à justiça se caracteriza como tarefa hercúlea, conforme asseveram Cappelletti e Garth:

[...] como fator complicador dos esforços para atacar as barreiras ao acesso, deve-se enfatizar que esses obstáculos não podem simplesmente ser eliminados um por um. Muitos problemas de acesso são inter-relacionados, e as mudanças tendentes a melhorar o acesso por um lado podem exacerbar barreiras por outro. Por exemplo, uma tentativa de reduzir custos é simplesmente eliminar a representação por advogado em certos procedimentos. Com certeza, no entanto, uma vez que litigantes de baixo nível econômico e educacional provavelmente não terão a capacidade de apresentar seus próprios casos, de modo eficiente, eles serão muito mais prejudicados que beneficiados por tal "reforma". Sem alguns fatores de compensação, tais como um juízo muito ativo ou outras formas de assistência jurídica, os autores indigentes poderiam agora intentar uma demanda, mas lhes faltaria uma espécie de auxílio que lhes pode ser essencial para que sejam bem-sucedidos. Um estudo sério do acesso à Justiça não pode negligenciar o inter-relacionamento entre as barreiras existentes (CAPPELLETTI; GARTH,1988, p. 11).

Para o Professor Boaventura, "a democratização da administração da justiça é uma dimensão fundamental da democratização da vida social, econômica e política", com dois enfoques: "participação dos cidadãos [...] na administração da justiça" e a própria democratização do acesso à justiça (SANTOS, 1986, p. 28-29).

Vale ressaltar três aspectos fundamentais depreendidos do Projeto Florença: a “origem da articulação entre o Welfare State (e sua crise) com o acesso à justiça"; [...] "a relação do acesso aos direitos e à justiça com os conflitos que envolvem a própria administração pública"; e a posição de destaque "que a educação para os direitos já ocupava" nos debates acerca do acesso à justiça (VITOVSKY , 2015, p. 10).

Percebe-se, de forma cristalina, que houve uma evolução no tocante ao acesso à justiça no Brasil nos últimos anos: "a criação dos juizados especiais, o fortalecimento das defensorias públicas e a ampliação dos legitimados pelo ajuizamento de ações coletivas. Mas é preciso fazer mais" (OLIVEIRA, 2012, on-line).

As medidas tomadas se mostraram insuficientes para garantir de forma ampla o acesso à justiça a toda a população:

Estas medidas de democratização, apesar de amplas, têm limites óbvios. A desigualdade da proteção dos interesses sociais dos diferentes grupos sociais está cristalizada no próprio direito substantivo, pelo que a democratização da 
administração da justiça, mesmo que plenamente realizada, não conseguirá mais do que igualar os mecanismos de reprodução da desigualdade. Há pouco, um jurista chileno dizia que não fazia sentido lutar pelo seu país pelo acesso à justiça por parte das classes populares já que o direito substantivo era tão discriminatório em relação a elas que a atitude política democrática consistia exactamente em minimizar o acesso. (SANTOS, 1986, p. 29).

Contudo, se temos a Constituição "mais democrática do mundo [...] e a que mais possui mecanismos de acesso à Justiça" (STRECK, 2009), devemos fazer cumpri-la, ou seja, garantir que os direitos nela previstos sejam efetivados, bem como garantir que toda a população tenha possibilidade de, sendo o caso, adentrar as portas do Judiciário para pleitear tais direitos.

Vale ressaltar ainda que a busca de soluções para a questão do acesso à justiça "não se deve limitar a eliminar obstáculos econômicos ao consumo da justiça por parte dos grupos sociais de pequenos recursos" (SANTOS, 1986, p. 28-29).

\subsection{Obstáculo Cultural}

Conforme mencionado acima, o obstáculo cultural é aquele relacionado à falta de conhecimento da população acerca dos seus direitos, principalmente a parcela mais desprovida de recursos, que é a que menos tem acesso à educação.

Maria Tereza Aina Sadek, baseada em pesquisas internacionais, aponta que as sociedades com "elevados índices de desigualdade econômica e social” tendem a ter "amplas camadas de sua população [...] caracterizadas pelo desconhecimento de direitos", o que “compromete a universalização do acesso à justiça" (SADEK, 2014, p. 58).

Lênio Streck lembra que "o texto constitucional de 1988 colocou à disposição do cidadão vários mecanismos de acesso à justiça” (STRECK, 2014, p. 87). Ocorre que grande parcela da população desconhece a maior parte de seus direitos.

Destarte, "os cidadãos de menores recursos tendem a conhecer pior os seus direitos e [...] reconhecer um problema que os afecta como sendo problema jurídico. Podem ignorar os direitos em jogo ou ignorar as possibilidades de reparação jurídica" (SANTOS, 1986, p. 21). 
Para se enfrentar o obstáculo cultural, faz-se necessária "a atribuição de promoção da difusão e da conscientização dos direitos humanos, da cidadania e do ordenamento jurídico" (REIS; ZVEIBIL; JUNQUEIRA, 2013, p. 18).

Insta frisar que os obstáculos enfrentados por cidadãos considerados "relativamente fracos, com causas relativamente pequenas" têm prejudicado o respeito a direitos. Tais indivíduos "frequentemente não têm conhecimento de seus direitos, não procuram auxílio ou aconselhamento jurídico e não propõem ações" (CAPPELLETTI; GARTH, 1988, p. 34).

Cabe ao poder público "eliminar os obstáculos sociais e culturais, esclarecendo os cidadãos sobre os seus direitos [...] através de consultas individuais e colectivas e [...] acções educativas nos meios de comunicação, nos locais de trabalho, nas escolas, etc." (SANTOS, 1986, p. 29).

É imperioso salientar a dificuldade de concretizar de forma individualizada esses "novos direitos substantivos das pessoas comuns. [...] Nem o movimento considerável e contínuo em defesa dos interesses difusos, nem as técnicas de diversificação podem atacar as barreiras à efetividade desses importantes novos direitos" (CAPPELLETTI; GARTH, 1988, p. 34).

\subsection{Acesso à Justiça no Brasil}

No escólio de Eugenio Raúl Zaffaroni, “dirimir conflitos é uma função judicial”, e "é necessário que os cidadãos gozem de um eficaz serviço judiciário e de um amplo acesso a ele" (ZAFFARONI, 1995, p. 35).

No entanto, o que se observa é a busca de acesso à justiça a grande parte da população, principalmente a população de baixa renda, os hipossuficientes. Aliás, é justamente "essa procura que está, hoje, em discussão. E se ela for considerada, vai levar a uma grande transformação do sistema judiciário no seu todo, tão grande que fará sentido falar da revolução democrática da justiça” (SANTOS, 2011, p. 38).

Para a maior parte da doutrina, o acesso à justiça se consubstancia em um direito fundamental. Neste sentido, é mister salientar, no ordenamento jurídico brasileiro, a consagração do princípio da universalidade (ou inafastabilidade) da jurisdição. 
Vale ressaltar que o princípio da universalidade da jurisdição, previsto no texto constitucional, no inciso XXXV do Artigo $5^{\circ}$, enuncia que "nenhuma lesão, ou ameaça de lesão ao direito, pode ser subtraída da apreciação do Judiciário; então tudo, tudo mesmo, pode ser levado diretamente ao Poder Judiciário” (LEWANDOWSKI, 2009, p. 81).

Destarte, o "alargamento do acesso ao Poder Judiciário, alinhado com as garantias constitucionais da assistência jurídica integral e gratuita e da inafastabilidade do controle jurisdicional, toma o rumo traçado pelo espírito democrático-participativo da $\mathrm{CF} / 88$ [...]" (FENSTERSEIFER, 2017, p. 111).

Urge frisar que "o direito internacional dos direitos humanos" considera "o direito à assistência jurídica integral e gratuita para as pessoas em condição de vulnerabilidade" como direito humano, "devendo, como tal, ser promovido e garantido pelo Estado" (MAZZUOLI, 2014, p. 236).

Conquanto o escólio de Norberto Bobbio seja no sentido de que não haveria direito fundamental absoluto (BOBBIO, 1992), talvez o acesso à justiça seja uma exceção a essa regra, uma vez que não estaria em conflito com nenhum outro direito fundamental; até porque o acesso à justiça, enquanto direito fundamental, seria um fim em si mesmo.

Dito de outra forma, o acesso à justiça estaria subjacentemente vinculado à ideia, como quer Hanna Arendt ${ }^{2}$, “da existência de um direito a ter direitos" (ARENDT, 1990, p. $330)$.

Levando-se em consideração o princípio da inafastabilidade da jurisdição, bem como o alto número de processos judiciais existentes no país ${ }^{3}$, seria possível concluir que não haveria problemas de acesso à justiça no país. Contudo, o que se constata na realidade é uma concentração de demandas (aliás, não coincidentemente, a mesma concentração observada na distribuição de renda).

De acordo com Lewandowski (2009, p. 81), “a Constituição de 1988 escancarou as portas do Poder Judiciário, primeiro porque deu efetividade, repetiu no seu texto o princípio da universalidade da jurisdição, procurando dar-lhe eficiência" (LEWANDOWSKI,

\footnotetext{
2 "Só conseguimos perceber a existência de um direito a ter direitos [...] quando surgiram milhões de pessoas que haviam perdido esses direitos e não podiam recuperá-los devido à nova situação política global" (ARENDT, 1990, p. 330).

${ }^{3}$ Conforme dados do Conselho Nacional de Justiça, o "Poder Judiciário finalizou o ano de 2017 com 80,1 milhões de processos em tramitação" (BRASIL, 2018, p. 72).
} 
2009, p. 81). Entretanto, o que se percebe é que a maior parte da população brasileira não tem garantido seu acesso à justiça.

Nesta senda, insta frisar a lição de Sadek:

Ademais, a demanda por direitos, longe de ser universal, provém de setores privilegiados da sociedade. Em consequência, dado o volume de processos e o perfil dos que postulam judicialmente, a instituição sofre de inchaço, cuja dilatação, além de dificultar sua atuação, contribui para a construção de uma imagem negativa junto à população. Em outras palavras, a porta de entrada atrai um tipo de litigante e desencoraja ou se fecha para a grande massa de indivíduos incapazes de manejar instrumentos de efetivação de seus direitos, produzindo um paradoxo: demandas de mais e demandas de menos. (SADEK, 2014, p. 59).

Nessa mesma linha é a opinião de Flávia Piovesan, que preleciona que o Poder "Judiciário deixa de ser utilizado para a garantia de direitos e passa a ser procurado principalmente para se obter vantagens". A utilização dele está relacionada à camada social "que dispõe de mais recursos econômicos, sociais e intelectuais" (PIOVESAN, 2014, p. 105).

$\mathrm{Na}$ concepção de Gabriel Faria Oliveira, Defensor Público-Geral Federal, o "Poder Judiciário não é elitista em sua essência. Porém, a dificuldade de acesso a este poder cumula com a disparidade entre as funções essenciais à Justiça e faz com que, inevitavelmente, seja desigual" (OLIVEIRA, 2012, on-line). E complementa mais adiante:

A Justiça, a priori, é um serviço público pago. Para acessá-lo, o cidadão deve arcar com as custas judiciais e também - regra - com a contratação de advogados que venham a patrocinar suas causas e defesas. Em muitos cantos do país existem convênios para a assistência judiciária e da advocacia pro bono, que são extremamente válidos e contributivos para a melhoria do acesso à Justiça e busca pela efetivação dos direitos. Não obstante, o altruísmo destas ações não pode significar uma alternativa estatal ao Direito fundamental do cidadão. A obrigação é do Estado e não de terceiros benevolentes. Trata-se do direito a ter direitos: o mínimo que, até então, vem sendo flagrantemente desrespeitado no âmbito da União. [...] $\mathrm{O}$ direito fundamental ao acesso à Justiça da Constituição Federal não pode ser encarado [...] como apenas uma alternativa. Já o foi durante todo este tempo e não faltam demonstrações de que o sistema de Justiça não está acessível ao cidadão mais pobre. O juro social está correndo. (OLIVEIRA, 2012, online).

No Brasil, os obstáculos ao acesso à justiça acabam impactando diretamente no descumprimento e desrespeito aos direitos fundamentais e sociais previstos no texto constitucional. Aliás, conforme dito anteriormente, o próprio acesso à justiça se consubstancia 
direito fundamental. Neste diapasão, Ingo Sarlet magistralmente assevera acerca do direito fundamental social à saúde:

[...] quando se considera que os recursos públicos deverão ser distribuídos para atendimento de todos os direitos fundamentais sociais básicos, sustentamos o entendimento, que aqui vai apresentado de modo resumido, no sentido de que sempre onde nos encontramos diante de prestações de cunho emergencial, cujo indeferimento acarretaria o comprometimento irreversível ou mesmo o sacrifício de outros bens essenciais, notadamente em se cuidando da saúde - da própria vida, integridade física e dignidade da pessoa humana, haveremos de reconhecer um direito subjetivo do particular à prestação reclamada em Juízo. Tal argumento cresce em relevância se tendo em conta que a nossa ordem constitucional (acertadamente, diga-se de passagem) veda expressamente a pena de morte, a tortura e a imposição de penas desumanas e degradantes mesmo aos condenados por crime hediondo, razão pela qual não se poderá sustentar - pena de ofensa aos mais elementares requisitos da razoabilidade e do próprio senso de justiça - que [...] se acabe virtualmente condenando à morte a pessoa cujo único crime foi o de ser vítima de um dano à saúde e não ter condições de arcar com o custo do tratamento. (SARLET, 2007, p. 13).

Desprovida de acesso à justiça, grande parte da população brasileira fica sem ter seus direitos fundamentais e sociais efetivados. Esses indivíduos, por exemplo, dependem de medicamento não oferecido pelo SUS e não têm condições de custear um advogado. Pode-se citar ainda "o pequeno agricultor que - por desconhecimento - produz em área de reserva ambiental e precisa de assistência" (OLIVEIRA, 2012, on-line).

De acordo com o entendimento de Mauro Cappelletti e Bryant Garth:

A grande tarefa dos reformadores do acesso à justiça é, portanto, preservar os tribunais ao mesmo tempo em que aperfeiçoam uma área especial do sistema judiciário que deverá alcançar esses indivíduos, atrair suas demandas e capacitá-los a desfrutar das vantagens que a legislação substantiva recente vem tentando conferir-lhes. [...] A preocupação fundamental é, cada vez mais, com a "justiça social", isto é, com a busca de procedimentos que sejam conducentes à proteção dos direitos das pessoas comuns. Embora as implicações dessa mudança sejam dramáticas - por exemplo, com relação ao papel de quem julga - é bom enfatizar, desde logo, que os valores centrais do processo judiciário mais tradicional devem ser mantidos. $\mathrm{O}$ "acesso à justiça" precisa englobar ambas as formas de processo (CAPPELLETTI; GARTH,1988, p. 34). 
Outrossim, Cleber Francisco Alves aduz que "a possibilidade de acesso efetivo aos tribunais torna-se um diferencial importante para a caracterização de uma verdadeira democracia, devidamente consolidada" (ALVES, 2005, p. 43).

Ainda, conforme Alves, "haveria um considerável incremento no patamar de democratização" se "a aplicação da lei não fosse apenas um privilégio dos integrantes dos estratos sociais mais bem aquinhoados economicamente" (ALVES, 2005, p. 43).

\section{A DEFENSORIA PÚBLICA COMO GARANTIDORA DO ACESSO À JUSTIÇA}

Conquanto a Emenda Constitucional 80/2014 (popularmente conhecida como "PEC das Comarcas") tenha estipulado um prazo de oito anos (ou seja, até 2022) para que todas as comarcas do país tenham defensores públicos, essa situação está longe de ser regularizada. Em que pese o prazo estar escoando, a maior parte das defensorias públicas não consegue atender às suas demandas por falta de defensores públicos.

É mister destacar, inicialmente, que a quantidade insuficiente de defensores públicos nos estados prejudica o acesso à justiça e alonga o tempo de processos judiciais da população carente. Isso porque a atuação dos defensores públicos é fundamental para que os hipossuficientes possam adentrar as portas do Poder Judiciário.

Neste diapasão, apresenta-se a crítica de Reis, Zveibil e Junqueira:

E é para que possa cumprir seu objetivo que a Defensoria Pública deve ser dotada de estrutura de excelência. O excluído não precisa de qualquer prestação para ser incluído, tampouco basta um serviço mediano para que possa defender seus direitos perante uma parte "incluída". É necessário mais: é preciso que o serviço tenha qualidade suficiente a compensar a exclusão, e isso só será realmente possível na medida em que as Defensorias Públicas sejam dotadas de estrutura e orçamento suficiente para tanto, com profissionais valorizados e que se identifiquem com as finalidades institucionais. Sem isso, o serviço prestado será, como já dito, apenas mais uma formalidade a legitimar a exclusão "via procedimento" (REIS; ZVEIBIL; JUNQUEIRA, 2013, p. 60).

Luis Roberto Barroso lembra que a função primordial da Defensoria Pública “é prestar assistência judiciária aos pobres, tanto em processos penais como cíveis. É extraordinário o espectro de atuação da Defensoria Pública, em quantidade e qualidade" (BARROSO, 2014, on-line). 


\section{Nesse sentido é o escólio de Tiago Fensterseifer:}

O nome atribuído à instituição - Defensoria Pública - carrega tal significado, na medida em que expressa a ideia de "defesa pública". Não há dúvida que a imposição constitucional de se assegurar ao indivíduo o exercício de seu direito de defesa em face de persecução penal promovida pelo Estado está na gênese e impulsionou a criação da Defensoria Pública. E, nesse alinhamento, até em razão da desproporção de forças que caracterizam a relação jurídica "vertical" entre cidadão e Estado, expressivamente potencializada no espectro da persecução penal e infracional - no qual o indivíduo exerce o seu direito de defesa tanto em face da autoridade policial quanto do Ministério Público -, nada mais adequado que outra instituição pública, especialmente para os indivíduos vulneráveis e desprovidos de recursos econômicos para custear advogado particular, cumpra o papel da defesa criminal e traga equilíbrio e isonomia para a relação processual-penal (FENSTERSEIFER, 2017, p. 90-91).

O que se constata é que em "lugares onde não há Defensoria Pública não há democracia. [...] Nossos políticos devem primar pela Defensoria Pública eficiente e autônoma" (LEITE, 2013, on-line).

A despeito da previsão constitucional da assistência integral e gratuita promovida pela Defensoria Pública, Cleber Francisco Alves magistralmente aduz:

Assim, embora o Brasil possua formalmente - já desde longa data, e ainda mais ampliado recentemente - um dos mais aprimorados sistemas de garantia de igualdade às pessoas pobres no acesso à Justiça, abrangendo tanto a representação em juízo, com isenção de todas as despesas e custas processuais respectivas, quanto a orientação e o aconselhamento jurídico de caráter preventivo em favor das pessoas incapazes de arcar com as despesas de contratação de um advogado privado, sistema esse que tem sua fundamentação em dispositivos da Constituição e das Leis, não se pode deixar de reconhecer que a realidade é bastante diferente. Dentre os Estados da Federação, poucos são aqueles em que se pode efetivamente afirmar que as Defensorias Públicas estão implementadas segundo o modelo estabelecido na Constituição. E, mesmo nesses Estados em que as Defensorias Públicas estão funcionando, diversas são as dificuldades de ordem funcional e operacional para que cumpram efetivamente com sua missão constitucional. Seja em virtude do número insuficiente de Defensores Públicos, seja em razão da falta de condições materiais, notadamente espaço físico e equipamentos mínimos necessários para uma boa prestação do serviço (ALVES, 2006, p. 234).

Neste diapasão, é imperioso salientar a importância do trabalho da Defensoria

Pública, pois a expansão da instituição contribui para a "obrigação constitucional do acesso à 
Justiça. Não por acaso, boa parte dos ministros do STF [...] ressaltaram a necessidade imediata de maior estruturação das Defensorias Públicas no país” (MAFFEZOLI; SOUZA, 2012).

Não se pode olvidar que a Defensoria Pública é imprescindível para a defesa dos direitos fundamentais da população carente, especificamente no tocante à assistência jurídica gratuita, uma vez que viabiliza o acesso dos vulneráveis à Justiça.

Nesta senda, apresenta-se a visão de Tiago Fensterseifer:

A Defensoria Pública, haja vista a sua identidade e papel constitucional, enquanto instituição promotora da cidadania, está visceralmente vinculada à defesa e promoção dos direitos das pessoas em condições de carência socioeconômica. A condição de vulnerabilidade, em linhas gerais, é resultado da falta de acesso de tais indivíduos e grupos sociais a condições mínimas de bem-estar (inclusive sob a perspectiva do direito-garantia ao mínimo existencial), ou seja, de acesso aos seus direitos sociais mais básicos, como saúde, educação, moradia, água e saneamento básico, alimentação, previdência, assistência social, transporte público, acesso à justiça, entre outros. O cenário descrito de "carências materiais" e de indignidade humana, infelizmente, é recorrente e está presente de forma significativa no contexto social brasileiro, no qual uma massa expressiva da população carente encontra-se sem acesso aos seus direitos sociais básicos, e, por consequência, a uma vida digna. Essa abordagem, considerando a desigual realidade brasileira, coloca para a Defensoria Pública, além da defesa judicial dos direitos sociais de tais pessoas - muitas vezes em demandas em face do próprio Estado, dada omissão dos poderes públicos em assegurar o desfrute de tais direitos -, um leque de possibilidades de atuação também no âmbito extrajudicial, como, por exemplo, por meio da fiscalização e da participação na gestão de políticas públicas, além de práticas de educação em direitos. Soma-se a isso tudo a matriz democrático-participativa que deve nortear a atuação da Defensoria Pública, de modo a manter permanente canal de diálogo com a sociedade civil e os movimentos sociais e legitimar a sua atuação a partir das demandas em matéria de direitos sociais que lhes são trazidas por tais entidades e mesmo por indivíduos isoladamente (FENSTERSEIFER, 2017, p. 99-100).

Segundo Alves, "as importantes medidas que vêm sendo tomadas ultimamente no Brasil [...] não serão suficientes nem adequadas para viabilizar a efetiva aproximação das classes mais pobres à Justiça" (ALVES, 2005, p. 44). Para efetivar a previsão constitucional "da assistência jurídica integral e gratuita [...] torna-se imprescindível dotar a Defensoria Pública de condições materiais e humanas e de instrumentos adequados para que possa cumprir sua missão constitucional de viabilizar o acesso à justiça" aos hipossuficientes (ALVES, 2005, p. 44). 
Bruno Shimizu e Rafael Folador Strano ressaltam a importância da atuação dos defensores públicos, mesmo contra o "sistema":

[...] anseia-se que o defensor público não se satisfaça ao reproduzir antigas práticas de defesa, que apenas legitimam um sistema socialmente desigual e excludente. Pretende-se que a norma, antes entendida como fonte primária e absoluta do Direito, seja lida à luz do contexto social em que se aplica. [...] Espera-se, outrossim, que o defensor não julgue o seu defendido e que tampouco deixe de pleitear algo que seja favorável àquele em razão de uma suposta "relação amigável" com as demais carreiras jurídicas ou, o que é mais comum, em razão de um suposto "bom senso" cobrado do defensor por outros atores do jogo processual, que nada mais é que um convite para que o defensor assuma-se enquanto mais uma peça no aparato penal estruturalmente opressor dos grupos perseguidos. A propósito, não custa lembrar que a missão atribuída ao defensor público é, de per si, antipática às demais carreiras jurídicas, já que tendem a relativizar todo o substrato em que aquelas se assentam durante séculos. (SHIMIZU; STRANO, 2013, p. 393).

Cleber Francisco Alves assevera que o futuro da instituição depende da “conscientização dos próprios membros da carreira, no sentido de que a eles cabe uma responsabilidade decisiva na edificação permanente da instituição. É fundamental um compromisso com o ideal de igualdade no acesso à Justiça” (ALVES, 2005, p. 300).

Nessa mesma esteira é o escólio de Tiago Fensterseifer:

À luz do novo paradigma sobre o qual opera o sistema jurídico atual e, consequentemente, os atores públicos e privados do nosso Sistema de Justiça, superando a tradição liberal individualista antes vigente [...], não pode a Defensoria Pública postar-se alheia a tudo isso. Ela é, por outro lado, no âmbito do Sistema de Justiça brasileiro, um dos principais agentes reformadores e renovadores. Assim, sem recuar qualquer espaço na sua atuação rotineira de casos individuais, a Defensoria Pública é chamada (pela própria ordem jurídica que a disciplina) a atuar também por meio dos instrumentos processuais (extrajudiciais e judiciais) coletivos, sendo um deles (o de mais destaque) a ação civil pública (FENSTERSEIFER, 2017, p. $110)$.

Destarte, é imprescindível para a concretização do acesso à justiça uma

Defensoria Pública bem estruturada (em todos os sentidos), com a previsão de, no mínimo, um defensor público por comarca. 


\section{CONSIDERAÇÕES FINAIS}

Conquanto tenha ocorrido uma notável evolução no tocante ao acesso à justiça, percebe-se com clareza solar que, mesmo decorridos quarenta anos da divulgação dos resultados do Projeto de Florença, a efetividade do acesso à justiça ainda está muito longe do ideal.

Conforme os princípios da inafastabilidade e da universalidade, todos os cidadãos, independentemente da classe econômica a que pertençam, devem ter garantido o seu acesso à justiça. Ocorre que devido a uma série de barreiras, há um cerceamento do acesso à justiça, especialmente para a parcela hipossuficiente da população. Vale ressaltar que essa hipossuficiência implica também a falta de conhecimento de tais indivíduos (obstáculo cultural) acerca dos direitos fundamentais que teriam.

A Defensoria Pública, responsável por garantir a assistência jurídica integral e gratuita à população hipossuficiente, precisa ser efetivamente estruturada, para poder atuar com toda a amplitude em prol de seus atendidos, conforme previsão constitucional.

Outrossim, à medida que a instituição for devidamente estruturada, cabe a cada defensor público atuar da melhor maneira possível, seja esclarecendo e divulgando os direitos que os indivíduos hipossuficientes possuem (mas desconhecem), seja proporcionando aos seus assistidos o melhor e mais amplo acesso ao Poder Judiciário.

\section{REFERÊNCIAS}

ALVES, Cleber Francisco. A estruturação dos serviços de assistência jurídica nos Estados Unidos, na França e no Brasil e sua contribuição para garantir a igualdade de todos no acesso à justiça. Rio de Janeiro: PUC-Rio, Departamento de Direito, 2005. Tese (Doutorado).

Justiça para todos! Assistência jurídica nos Estados Unidos, na França e no Brasil. Rio de Janeiro: Editora Lumen Juris, 2006.

ARENDT, Hannah. Origens do totalitarismo: antissemitismo, imperialismo, totalitarismo. Tradução de Roberto Raposo. Companhia das Letras, 1990.

BARROSO, Luis Roberto. Justiça, empoderamento jurídico e direitos fundamentais. 2014. Disponível em: <http://www.luisrobertobarroso.com.br/wpcontent/uploads/2014/06/ONU_Justica-Empoderamento-legal-e-direitosfundamentais_versao-em-portugues.pdf $>$. Acesso em: 1 jan. 2019. 
BOBBIO, Norberto. A era dos direitos. Tradução de Carlos Nelson Coutinho. Rio de Janeiro: Editora Campus, 1992.

BRASIL. Conselho Nacional de Justiça. Justiça em números 2018: ano-base 2017. Brasília: CNJ, 2018.

CANOTILHO, J. J. Gomes. Direito constitucional e teoria da constituição. 7. ed. Coimbra: Almedina, 2003.

CAPPELLETTI, Mauro; GARTH, Bryant. Acesso à justiça. Tradução e revisão: Ellen Gracie Northfleet. Porto Alegre: Sergio Antonio Fabris Editor, 1988.FENSTERSEIFER, Tiago. Defensoria pública na Constituição Federal. Rio de Janeiro: Forense, 2017.

LEITE, Rosana. A defensoria pública e a sociedade. Anadep: 2013. Disponível em: <https://www.anadep.org.br/wtk/pagina/materia?id=16461>. Acesso em: 1jan. 2019.

LEWANDOWSKI, Enrique Ricardo. O protagonismo do poder judiciário na era dos direitos. Revista de Direito Administrativo. Rio de Janeiro: 2009. Disponível em: < http://bibliotecadigital.fgv.br/ojs/index.php/rda/article/viewFile/7529/6043>. Acesso em: 30 dez. 2018.

MACHADO, Tarcijany Linhares Aguiar. O acesso à justiça e as necessidades jurídicas. Defensoria pública e acesso à justiça, v. 3, n. 11, 2017.

MAFFEZOLI, Antonio; SOUZA, Rafael Morais Português de. Acesso à justiça. Disponível em: <https://www.anadep.org.br/wtk/pagina/materia?id=14655>. Acesso em: 1 jan. 2019.

MAZZUOLI, Valerio de Oliveira. Curso de direitos humanos. Rio de Janeiro: Forense; São Paulo: Método, 2014.

OLIVEIRA, Gabriel Faria. Justiça para quem não pode pagar. Conjur: 2012. Disponível em: <https://www.conjur.com.br/2012-mai-18/gabriel-faria-oliveira-justica-quem-naopagar>. Acesso em: 5 jan. 2019.

PASOLD, Cesar Luiz. Metodologia da pesquisa jurídica: teoria e prática. 13. ed. Florianópolis: Conceito Editorial, 2015.

PIOVESAN, Flávia. Poder Judiciário e os direitos humanos. Revista USP, n. 101. São Paulo: Março/abril/maio 2014.

REIS, Gustavo Augusto Soares dos; ZVEIBIL, Daniel Guimarães; JUNQUEIRA, Gustavo. Comentários à lei da defensoria pública. São Paulo: Saraiva, 2013.

SADEK, Maria Tereza Aina. Acesso à justiça: um direito e seus obstáculos. Revista USP, n. 101. São Paulo: Março/abril/maio 2014. 
SANTOS, Boaventura de Sousa. Introdução à sociologia da administração da justiça. Revista Crítica de Ciências Sociais, n. 21, nov. 1986.

Para uma revolução democrática da justiça. São Paulo: Cortez, 2011.

SARLET, Ingo Wolfgang. Algumas considerações em torno do conteúdo, eficácia e efetividade do direito à saúde na constituição de 1988. Revista eletrônica sobre a reforma do estado, n. 11. Salvador: set./out./nov. 2007.

SHIMIZU, Bruno; STRANO, Rafael Folador. O defensor público e a criminologia: da "desalienação" à resistência. In: RÉ, Aluisio Iunes Monti Ruggeri (org.). Temas aprofundados da Defensoria Pública. Salvador: Editora Juspodivm, 2013.

STRECK, Lênio Luiz. A baixa constitucionalidade como obstáculo ao acesso à justiça em Terrae Brasilis. Sequência, n. 69, p. 83-108. Florianópolis: UFSC, 2014.

Ativismo judicial não é bom para a democracia. Disponível em: $<$ https://www.conjur.com.br/2009-mar-15/entrevista-lenio-streck-procurador-justica-riogrande-sul>. Conjur: 2009. Acesso em: 31 dez. 2018.

VITOVSKY, Vladimir Santos. O acesso à justiça no novo código de processo civil: continuidades, inovações e ausências. Revista CEJ, Brasília, Ano XIX, n. 67, p. 7-17, set./dez. 2015.

ZAFFARONI, Eugenio Raúl. Poder Judiciário: crises, acertos e desacertos. Tradução de Juarez Tavares. São Paulo: Revista dos Tribunais, 1995. 